\title{
Newborn Incubators Do Not Protect from High Noise Levels in the Neonatal Intensive Care Unit and Are Relevant Noise Sources by Themselves
}

\author{
Tanja Restin 1,2,*(D), Mikael Gaspar ${ }^{2}$, Dirk Bassler ${ }^{1}$, Vartan Kurtcuoglu ${ }^{2}$, Felix Scholkmann ${ }^{1,+}$ (D) \\ and Friederike Barbara Haslbeck ${ }^{1,+}$ \\ 1 Department of Neonatology, Newborn Research Zurich, University Hospital Zurich, \\ 8091 Zurich, Switzerland; Dirk.Bassler@usz.ch (D.B.); Felix.Scholkmann@usz.ch (F.S.); \\ friederike.haslbeck@usz.ch (F.B.H.) \\ 2 Institute of Physiology, University of Zurich, 8057 Zurich, Switzerland; Mikael.Gaspar@gmail.com (M.G.); \\ Vartan.Kurtcuoglu@uzh.ch (V.K.) \\ * Correspondence: Tanja.Restin@uzh.ch \\ + These authors contributed equally to this work.
}

\section{check for}

updates

Citation: Restin, T.; Gaspar, M.; Bassler, D.; Kurtcuoglu, V.;

Scholkmann, F.; Haslbeck, F.B.

Newborn Incubators Do Not Protect from High Noise Levels in the

Neonatal Intensive Care Unit and Are Relevant Noise Sources by

Themselves. Children 2021, 8, 704.

https://doi.org/10.3390/children 8080704

Academic Editor: Fabia Franco

Received: 25 May 2021

Accepted: 13 August 2021

Published: 16 August 2021

Publisher's Note: MDPI stays neutral with regard to jurisdictional claims in published maps and institutional affiliations.

Copyright: (c) 2021 by the authors. Licensee MDPI, Basel, Switzerland. This article is an open access article distributed under the terms and conditions of the Creative Commons Attribution (CC BY) license (https:/ / creativecommons.org/licenses/by/ $4.0 /)$.

\begin{abstract}
Background: While meaningful sound exposure has been shown to be important for newborn development, an excess of noise can delay the proper development of the auditory cortex. Aim: The aim of this study was to assess the acoustic environment of a preterm baby in an incubator on a newborn intensive care unit (NICU). Methods: An empty but running incubator (Giraffe Omnibed, GE Healthcare) was used to evaluate the incubator frequency response with 60 measurements. In addition, a full day and night period outside and inside the incubator at the NICU of the University Hospital Zurich was acoustically analyzed. Results: The fan construction inside the incubator generates noise in the frequency range of $1.3-1.5 \mathrm{kHz}$ with a weighted sound pressure level (SPL) of $40.5 \mathrm{~dB}(\mathrm{~A})$. The construction of the incubator narrows the transmitted frequency spectrum of sound entering the incubator to lower frequencies, but it does not attenuate transient noises such as alarms or opening and closing of cabinet doors substantially. Alarms, as generated by the monitors, the incubator, and additional devices, still pass to the newborn. Conclusions: The incubator does protect only insufficiently from noise coming from the NICUThe transmitted frequency spectrum is changed, limiting the impact of NICU noise on the neonate, but also limiting the neonate's perception of voices. The incubator, in particular its fan, as well as alarms from patient monitors are major sources of noise. Further optimizations with regard to the sound exposure in the NICU, as well as studies on the role of the incubator as a source and modulator, are needed to meet the preterm infants' multi-sensory needs.
\end{abstract}

Keywords: newborn incubators; neonatal intensive care unit; noise; sound

\section{Introduction}

Newborns born preterm require special care and spend days and sometimes even months in neonatal units equipped with incubators and monitoring tools supporting as well as controlling the infants' cardiorespiratory function and temperature regulation. These devices contain noise sources, including alarms, switches and fans. Such environmental noise is known to disturb recreation and sleep [1], may lead to long-term hearing loss [2], and has been identified as a potential risk factor for worse neurological development [3] That environmental noise retards auditory cortical development has been shown in animal experiments [4]. On the other hand, auditory deprivation appears to be a risk factor for unfavorable neurological outcomes [5], while meaningful sound exposure such as music or language may improve the neuronal connectivity [6] and language skills of premature babies [7]. 
The fetal response to auditory stimuli starts at 19 weeks of pregnancy, enabling the newborn to hear sounds with a frequency up to $500 \mathrm{~Hz}$ (for comparison: the most common current concert pitch is $440 \mathrm{~Hz}$ ). The transmission of frequencies above $500 \mathrm{~Hz}$ are limited by the amniotic fluid and the mother's uterus and surrounding tissue [8]. In parallel with the further development of the neonate, the auditory frequency range increases up to $20 \mathrm{kHz}$ when maturing to term [9]. This maturation process has to take place within the extrauterine environment in the case of premature delivery. New synaptic connectivity has been recently shown to be promoted by acoustic stimuli [6].

Studies demonstrate that preterm newborns may awake in reaction to sound pressure peaks equivalent to 5-10 dB(A) above background noise [1]. Despite this knowledge, unfortunately, little attention has been paid to the auditory surrounding of premature babies. Extrapolation of adult data led the American Association of Pediatrics to recommend to maintain weighted sound pressure levels (SPL) below $45 \mathrm{~dB}(\mathrm{~A})$ in neonatal intensive care units (NICU) [10]. However, evaluating the noise data in different units demonstrated SPLs that often surpass this threshold [11]. Nevertheless, sound pressure levels alone do not reflect whether a sound is perceived as comforting or disturbing-it might even be difficult to sleep in the presence of a buzzing mosquito, which usually does not elicit sound pressure levels higher than $40 \mathrm{~dB}(\mathrm{~A})$ [12]. From a structured literature research using the databases Pubmed, EMBASE, and Web of Science in July 2021, 500 reports on "noise and NICU" could be retrieved (Appendix A). These publications demonstrate that noise impacts on newborns, parents and the staff [13-17]. They often either focus on the reduction of noise $[13,18]$ or at the enrichment of the acoustic environment $[19,20]$. Many studies rely on spot measurements of sound pressure levels and do not consider any frequencies. The incubator itself muffles environmental noise [21] while at the same time exposing the newborn to artificial sounds (e.g., fan noise, door opening and closing sounds). The exact frequency response of an incubator has not been published so far. Here, we therefore aimed to characterize the typical acoustic environment of a preterm baby in an NICU. Our results may be of value for optimizing NICU acoustics to enable optimal development of the neonate.

\section{Methods}

\subsection{Measurement Setup and Equipment}

This study assessed the acoustics inside and outside a running empty incubator (Giraffe Omnibed, GE Healthcare, Ohmeda Medical, Laurel, MD, USA). For all measurements, a calibrated measurement microphone (XREF2, Sonarworks, Riga, Latvia) with a usable bandwidth ranging from 20 to $20 \mathrm{kHz}$ was positioned at the level of the infant's head inside the incubator $10-15 \mathrm{~cm}$ above the mattress at an angle of $30-45^{\circ}$ and in the longitudinal axis as illustrated in Figure $1 \mathrm{~b}$. To record sound outside the incubator, a second microphone (BCM104, Neumann, Berlin, Germany) with a usable free field bandwidth from $80 \mathrm{~Hz}$ to $1.5 \mathrm{kHz}$ was placed at a distance of $20-30 \mathrm{~cm}$ from the incubator and $10-15 \mathrm{~cm}$ above the mattress. We define the usable bandwidth as the range in which frequency-dependent gain variations are below $2 \mathrm{~dB}$.

The measurements were performed in three steps: First, the frequency response of the incubator was characterized. Second, different noise sources that commonly occur in an NICU were assessed. Third, the acoustics at our open bay NICU at the University hospital Zurich were directly measured inside and outside the incubator during clinical routine. 

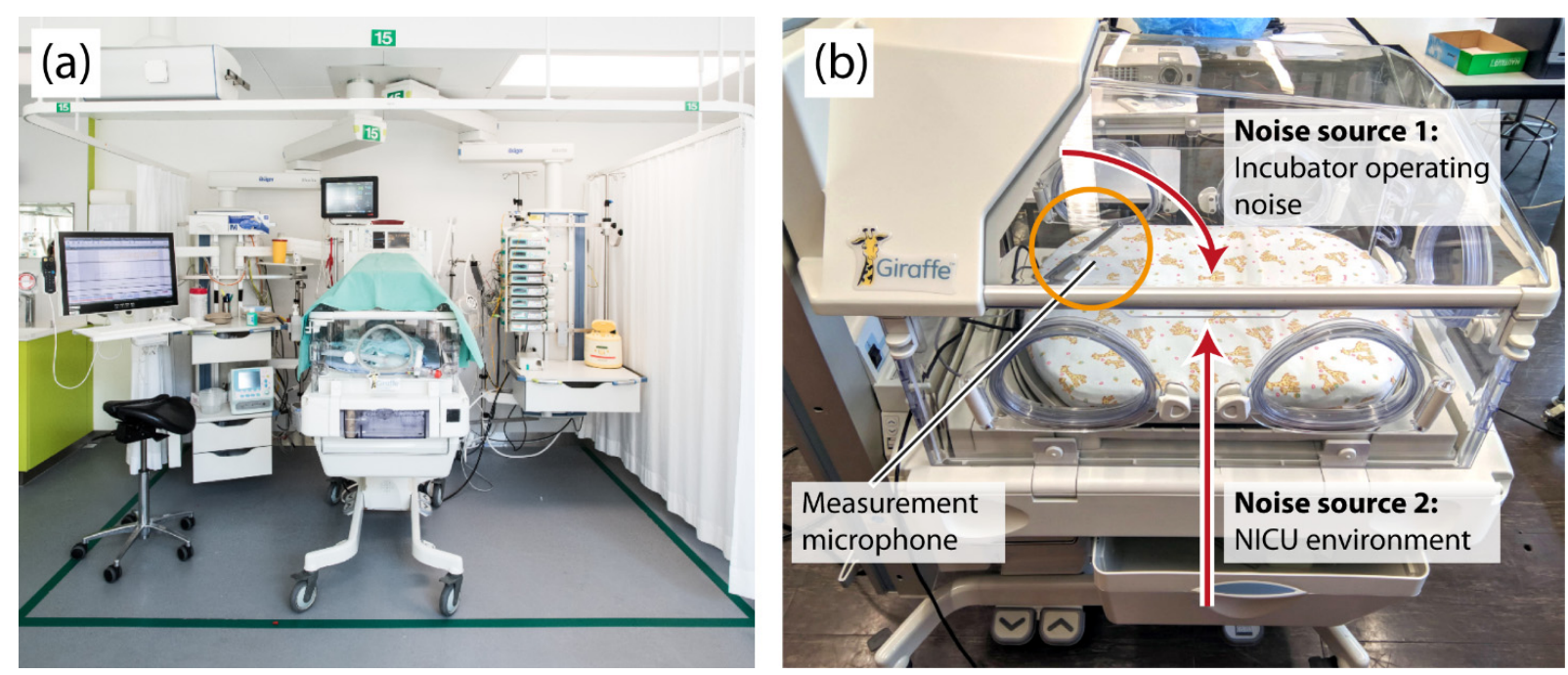

Figure 1. (a) Incubator in an NICU. In the picture, half of the top of the incubator is covered by a blanket to decrease the brightness inside the incubator. Image source: University Hospital Zurich; with permission. (b) Close-up of the incubator used in the study. The paths of two main sources of noise for the incubator are indicated by red arrows: sound coming from outside and inside. The orange circle indicates the position of the measurement microphone.

\subsection{Acoustic Properties of the Incubator}

In order to characterize the incubator's frequency response, we performed 60 measurements ranging from $30 \mathrm{~s}$ to $2 \mathrm{~min}$ in a semi-anechoic room, which was compared to the same measurements in 2 office rooms and inside the hospital. As blankets on top of the incubator are commonly used (Figure 1a), the effect of this measure was evaluated as well.

\subsection{Transfer of Noise into the Incubator}

Using the same equipment described above, we measured the noise generated by regular activities such as opening and closing the access doors of the incubator, opening the lid or refilling the water tank. Additionally, the transfer of monitor alarms as generated by the monitoring system (IntelliVue MX550, Philips, Amsterdam, The Netherlands) were measured.

\subsection{Characterization of the Environmental Noise at the NICU}

To assess for the acoustic environment at our NICU during clinical routine procedures, we evaluated intermittently $35 \mathrm{~h}$ and $14 \mathrm{~min}$ comprising five random time points, finally covering a full day and night period outside and inside the incubator positioned at the NICU at the Department of Neonatology at the University Hospital in Zurich, Switzerland. This NICU has an open bay design (Figure 1a).

\subsection{Data Recording and Processing}

Data were recorded uncompressed in Waveform Audio File format at a bit depth of 16 bit and with a sampling rate of at least $48 \mathrm{kHz}$. Data processing was performed in Matlab R2019a (Mathworks, Natick, MA, USA).

\section{Results}

\subsection{Acoustic Properties of the Incubator}

After the start-up procedure, the incubator produces noise in specific frequency bands, i.e., a very low-frequency noise in the range of $20-30 \mathrm{~Hz}$, a $100 \mathrm{~Hz}$ hum (most likely attributable to the transformer) and two constant high-frequency noise components in the range of $1.3-1.7 \mathrm{kHz}$ as well as at $3 \mathrm{kHz}$. Inside the incubator, the SPL was $34.7 \pm 0.5 \mathrm{~dB}(\mathrm{~A})$ when the incubator was switched off and $40.5 \pm 0.5 \mathrm{~dB}(\mathrm{~A})$ after the device completed the 
start-up procedure. The characteristic spectral signatures of the incubator are displayed in Figure 2a. The origin of the detected noise within a frequency range of $1.3-1.5 \mathrm{kHz}$ with weighted SPL of $40.5 \mathrm{~dB}(\mathrm{~A})$ is the incubator's fan. This ventilation system masks sounds originating outside the incubator with SPL less than 50-55 dB(A). Additionally, the attenuation of sound passing into the incubator is frequency dependent, which is further discussed below. With the doors closed, the incubator's architecture and material did not induce any dampening of sound or noise at frequencies below $250 \mathrm{~Hz}$. Above $250 \mathrm{~Hz}$, SPL was reduced by $15 \mathrm{~dB}$ on average. The incubator properties with respect to sound transmission from the outside to the inside were identical no matter whether the sound transfer was measured in the semi-anechoic room or in the NICU, as displayed in Figure 3a. The use of a blanket on top of the incubator provided only little benefit in reducing sound transmission above $2 \mathrm{kHz}$. Modification of the amplitude spectrum in the incubator was dependent on the amount of area covered by the blanket.

(a) Sounds generated during the start-up of an incubator (GE Giraffe OmniBed)

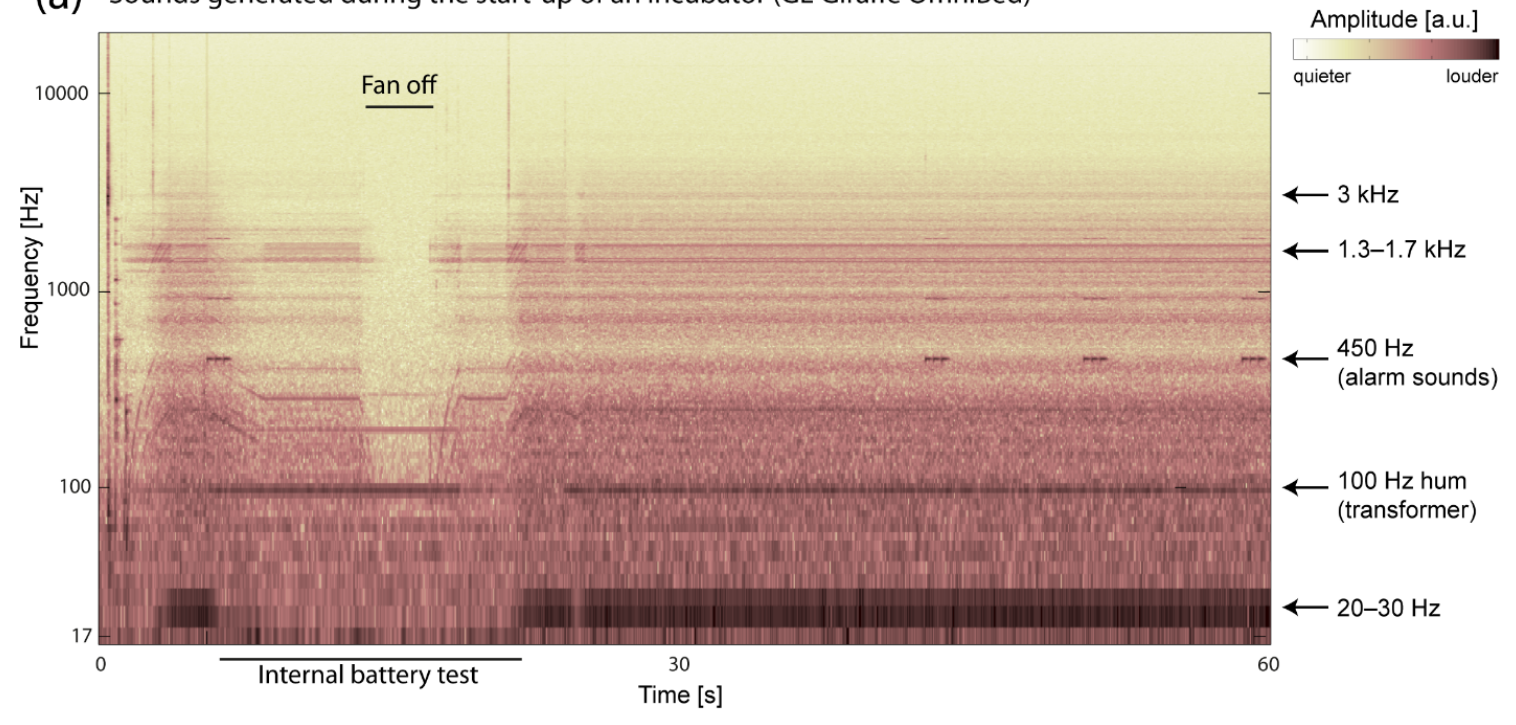

(b) Warning sounds (four levels)

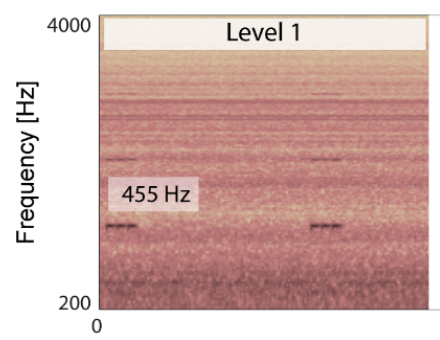

(c) Danger sounds (four levels)

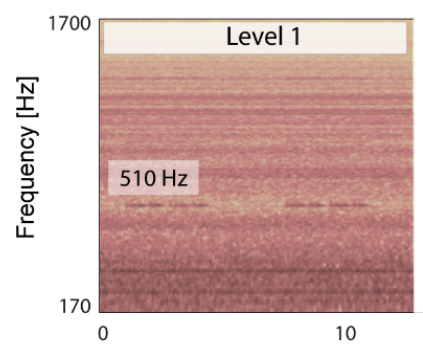

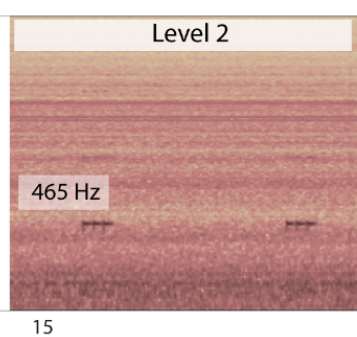

15
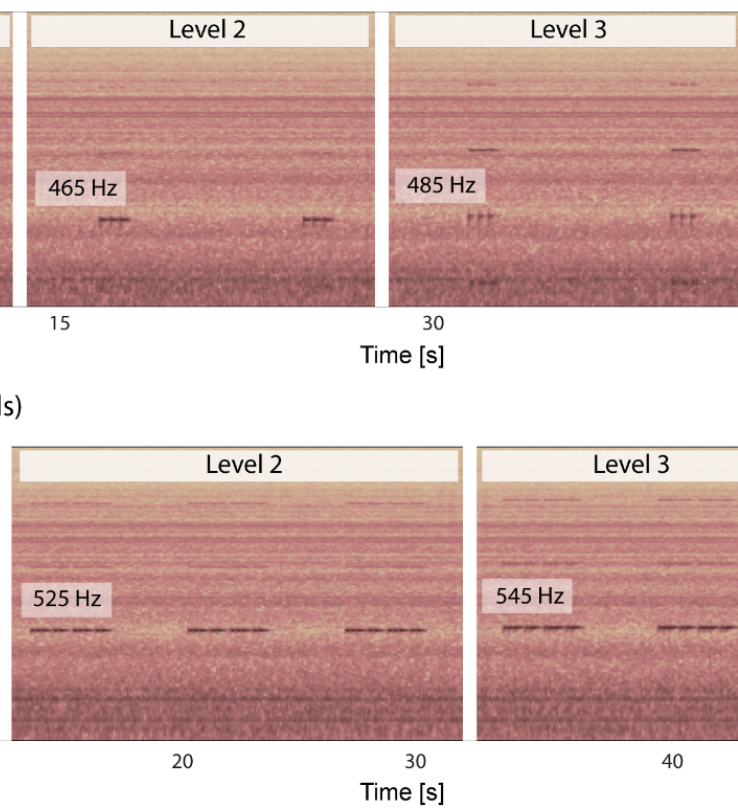

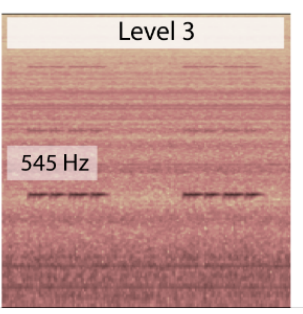

40

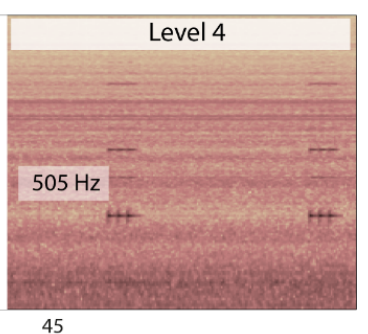

45

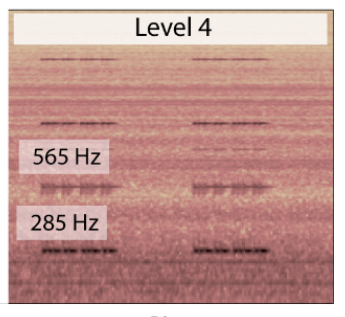

50

Figure 2. (a) Spectrogram of the noise produced by the incubator during the start-up phase. (b,c) Spectrograms of the warning and danger sounds produced by the IntelliVue MX550, Philips monitor next to the incubator. 

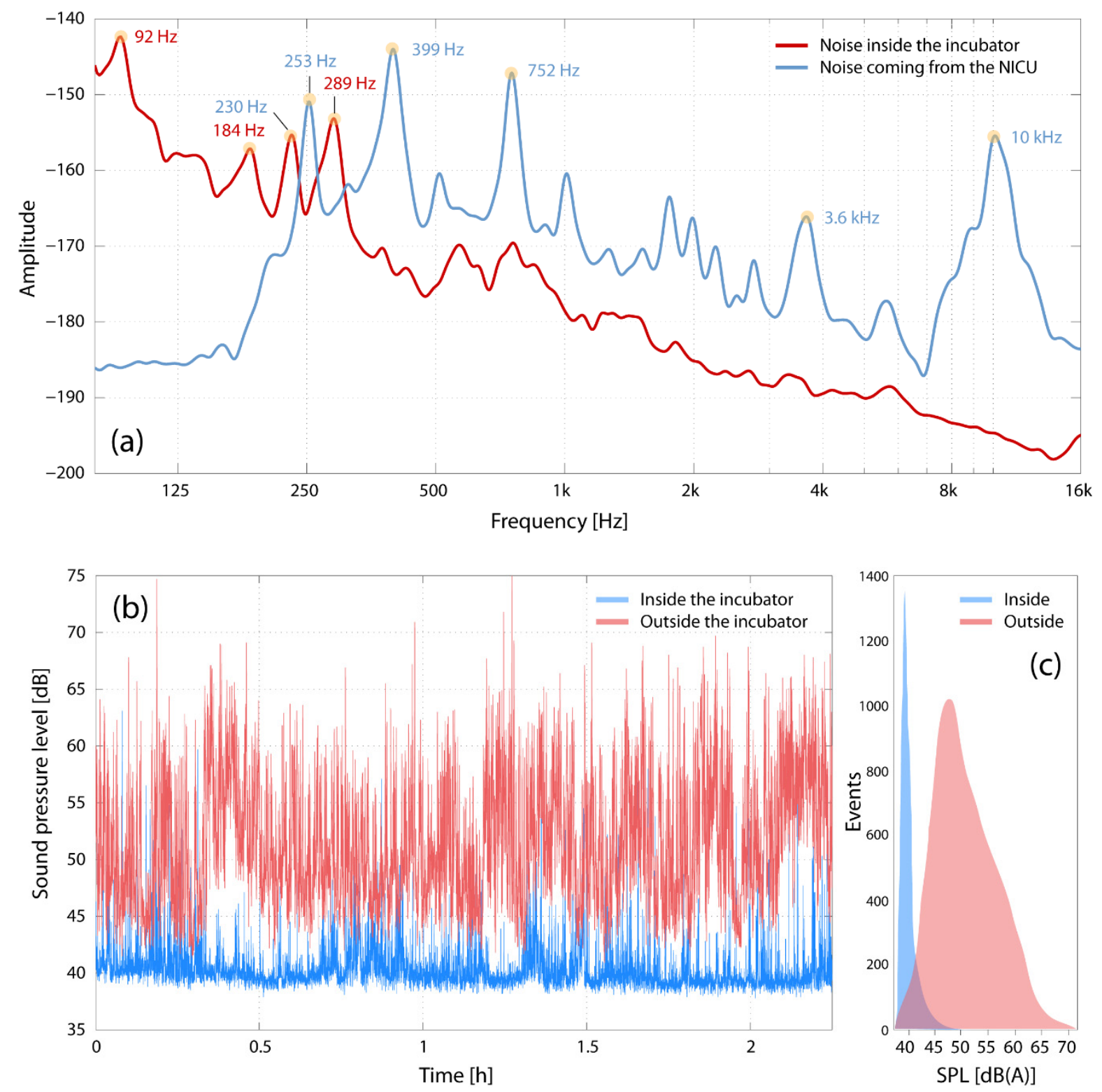

Figure 3. (a) Noise spectra recorded inside and outside an incubator located in an NICU. Peak frequencies are indicated at the specific peaks. The recording was done in an NICU with several incubators working and under normal clinical working conditions. (b) Time-series of SPL variations over about $2 \mathrm{~h}$, measuring inside and outside an incubator. (c) Distribution of SPL values shown in (b).

\subsection{Transfer of Noise into the Incubator}

The noise inside the incubator has a strong low-frequency component (at about 20-250 Hz) with a larger amplitude than the noise in the NICU. Sound at frequencies above approximately $300 \mathrm{~Hz}$ is attenuated markedly as it passes into the incubator. The temporal characteristics of noise inside and outside the incubator differ (Figure 3b,c), with the inside showing a narrow range of sound pressure levels (SPL: $40.4 \pm 2.2 \mathrm{~dB}(\mathrm{~A})$ ) than the outside (SPL: $51.2 \pm 5.6 \mathrm{~dB}(\mathrm{~A})$ ). Opening and closing of one door added $30 \mathrm{~dB}(\mathrm{~A})$, while the closing of one door while another was open led to a $15 \mathrm{~dB}(\mathrm{~A})$ increase in SPL. Opening the incubator on one side, as done for X-ray evaluation, causes an SPL increase of $15-20 \mathrm{~dB}(\mathrm{~A})$ and closing it of $38-42 \mathrm{~dB}(\mathrm{~A})$, both during less than $0.4 \mathrm{~s}$. We further found that the incubator water tank is an additional unexpected source of the noise. Its closure causes a transient sound of approximately $0.3 \mathrm{~s}$ duration with a sound pressure 
level exceeding $70 \mathrm{~dB}(\mathrm{~A})$. Opening and closing the top (as done for catheter insertion or complex intubation procedures) causes sound peaks beyond $70 \mathrm{~dB}$ for approximately $0.5 \mathrm{~s}$ and $0.3 \mathrm{~s}$, respectively.

Placing a plastic box on top of the incubator, a procedure not recommended but commonly discussed in the literature or observed (positioning of disinfectant or injection cannulas) yielded events above $80 \mathrm{~dB}(\mathrm{~A})$, lasting for periods less than $0.3 \mathrm{~s}$. The Philips IntelliVue MX550 monitor positioned next to each incubator generates a warning and a danger sound depending on the circulatory monitoring of the patient. Warning sounds were measured at $480 \mathrm{~Hz}$ (blue and orange alarm) and danger sounds were measured at $960 \mathrm{~Hz}$ (for the red alarm). Modes above harmonics are visible in the spectrogram up to $11 \mathrm{kHz}$ (Figure 2b,c).

\subsection{Characterization of the Environmental Noise at the NICU}

The average weighted SPL during acoustic evaluation at the NICU measured next to the incubator was $53 \mathrm{~dB}(\mathrm{~A})$. During more than half $(54 \%)$ of the whole measurement time at the NICU it was above $45 \mathrm{~dB}(\mathrm{~A})$. During the recordings at the NICU outside the incubator, we detected 194 occurrences of weighted SPL exceeding $65 \mathrm{~dB}(\mathrm{~A})$, most of which were of short duration $(<0.4 \mathrm{~s})$ and attributed to the opening and closing of a cabinet at the entrance of the NICU.

\section{Discussion, Conclusions, and Outlook}

\subsection{Acoustic Properties of the Incubator}

Our data demonstrate that despite the progress made in incubator technologies reducing the noise SPL from 70-80 dB(A) to $44 \mathrm{~dB}(\mathrm{~A})$ within the last 40 years, newborns within an incubator in the NICU are still exposed to high noise levels [22-24]. Even in the absence of additional noise from sources other than the incubator fan, the preterm environment would not meet the recommendations of the World Health Organization for community noise, which state that continuous background noise levels should not exceed $35 \mathrm{~dB}(\mathrm{~A})$ during sleep and individual noise events should not exceed $45 \mathrm{~dB}(\mathrm{~A})$ [25]. Since then, these standards have been repetitively integrated in the current recommendations for environmental standards in NICUs [26-29]. The frequency range of the measured constant fan noise, i.e., $1.3-1.5 \mathrm{kHz}$, partially overlaps with the frequencies covering the range of human speech [30]. Although the audible range lies between $20 \mathrm{~Hz}$ and $20 \mathrm{kHz}$ in humans, speech can be regularly identified within the more narrow band width between $300 \mathrm{~Hz}$ and $3.4 \mathrm{kHz}$, which therefore has been used as the "telephone bandwidth" according to the standards of the International Telecommunication Union [31,32]

Additionally, frequency-dependent attenuation changes the amplitude spectrum of speech as the corresponding sounds enter the incubator. According to Fletcher et al. (1923), the intelligibility of speech depends on the sum of different frequency bands, speech intensity, and temporal properties of the stimulus [33,34]. Consequently, the reduction of speech loudness by $15 \mathrm{~dB}(\mathrm{~A})$ at frequencies above $250 \mathrm{~Hz}$ will impair the transfer of speech into the incubator. If a person talks to a newborn inside the incubator, the incubator-related reduction of the spectral bandwidth will interfere with speech intelligibility. As a result, sound transfer will be impaired, which is in line with the findings of French et al. [35]. Therefore, if a caregiver wants to read or sing to the child, the side port of the incubator should be opened. Additionally, the lower frequencies will be better audible than higher, which might explain why in a recent analysis the exposure to mothers' voices led inside an incubator induced less relaxing physiological reactions in the newborns compared to white noise exposure [36].

\subsection{Transfer of Noise into the Incubator}

However, although each incubator does not produce sound exceeding $45 \mathrm{~dB}(\mathrm{~A})$, it is not taken into account that the aggregation of different machines in the NICU and the effect of further noise sources, such as an incubator port or cabinet door openings, cumulate 
together and produce a noisy atmosphere, masking meaningful speech and sound directed toward the newborn. In addition, the transfer of respirator tubings and cables via the small open side ports may generate noise, especially if the tubings have an irregular surface as is the case with accordion-tube design. These noise intensities will differ depending on how gently the cables are handled. The fact that opening of the first and closing of the last incubator entry port multiplied the loudness by more than the factor of $10(35 \mathrm{~dB}(\mathrm{~A}))$ can be attributed to the lack of a decompression system. Healthy newborns have shown to wake up in response to $3 \mathrm{~min}$ of mixed noise exposure between $100 \mathrm{~Hz}$ and $7 \mathrm{kHz}$ at sound levels of 70-75 $\mathrm{dB}$ [37]. However, it is likely that preterm and sick patients are more vulnerable [38].

Our data show that preterm infants are exposed to arguably high and diffuse noncontingent auditory overstimulation. Cotton covers may help against light, but they do not considerably reduced infant noise exposure in contrast to more noise absorbing polyurethane foam panels evaluated by Bellieni et al. [39]. Nonetheless, better insulating panels do not protect from fan noise that originates inside the incubator [39]. There is only one randomized controlled trial to reduce noise so far. However, in this small newborn cohort, silicone ear plugs may have been effective in the reduction of noise exposure $[13,40]$. However, they will not protect against respirator-associated noise transferred via bone conduction and will not help in distinguishing noise from sound, either. If monitor providers would predominantly use alarms at higher frequencies, the corresponding sounds would be attenuated more strongly as they pass into the incubator. However, when lying in the warmer or the arms of the parents, alarms would still disturb the infants, families, and NICU staff, so that visual or sensory alarms might be an alternative option to reduce noise [41]. In order to ensure persistent noise reduction, repetitive training and increased awareness of the personnel is very important; otherwise, the effect of improvements will get lost [42].

\subsection{Characterization of Environmental Noise at the NICU}

Empirically, based on our own observations, the number of noisy technical devices, the patient turnover, and visiting times of relatives and personnel has increased during the last several years. All these procedures may contribute to the increased background noise measured in our NICU. Correspondingly, Busch-Vishniak et al. [43] found "a clear trend for rising hospital noise levels" since 1960 at a rate of $0.38 \mathrm{~dB}$ per year for daytime levels and of $0.42 \mathrm{~dB}$ per year for nighttime levels. NICU noise levels are still reported to range from 54 to $60 \mathrm{~dB}(\mathrm{~A})$ [44], reaching peaks of $120 \mathrm{~dB}$ and exceeding recommended sound levels more than $70 \%$ of the time [45]. Berg et al. [46] underline these observations demonstrating peak noise levels between 82 and $102 \mathrm{~dB}(\mathrm{~A})$, particularly during visiting hours and medical rounds, and peak noise levels around $75 \mathrm{~dB}$ originating in alarms and other technical devices. In their systematic reviews, $\mathrm{O}^{\prime}$ Callaghan [47] and Veenendaal et al. [48] argue for an "evidence-based design" of NICUs, where single family rooms seem to have advantages concerning the environmental noise control [49-54]. One issue that is beyond the scope of our analysis is the noise generation by different systems used for newborn respiratory support. Ventilators for mechanical ventilation and non-invasive respiratory support systems both generate significant sound pressure levels up to $100 \mathrm{~dB}$ when measured in the postnasal space [55], depending on the device characteristics [56] and on the flow rate and amplitudes that are used [55]. Unlike external noise, which may be reduced by protective devices, there is nearly no attenuation of sound transfer via bone conductance [57]. Surenthiran also measured the in-the-ear noise intensities at $1 \mathrm{kHz}$, which showed a mean noise of $55 \mathrm{~dB}$ SPL if $5 \mathrm{~L}$ flow per minute was used with a device for continuous positive airway pressure [55]. To our knowledge, there is no qualitative measurement of NICU environmental sound that might distinguish disturbing, irregular noise from meaningful sound exposure. Interestingly, the same sound may be interpreted as comforting sound or annoying noise depending on the individual situation [58,59], associated expectations and interpretation [6,60], and the cultural background [61]. Some 
people have shown a higher noise sensitivity [62], with an estimated hereditability of about $30 \%$ [63]. That is why intensive care should become more personalized and humane to generate a positive basic atmosphere [64].

Therefore, the assessment of what is comfortable and what is not for an individual patient can only be based on close observation of the preterm. In contrast to adults where the sleeping time concentrates on several hours during the night, newborns have irregular sleeping patterns without an established circadian rhythm [65], which makes the organization of an open ward even more challenging. In order to adapt the acoustical environment to each patient's needs, we would need a flexible acoustic environment in each patient zone, which could be realized with advanced acoustic curtains. Since familycentered care increases interaction between parents and staff, the communication has to be properly dosed in order to provide rest and recreation for neighboring families. A recent review of intensive care unit built environments addresses this problem [15]. Studies suggest that parental vocal qualities are commonly adapted to their infants' behavioral state [66], which is why an attenuation of either the infants' state and/or the parental voice by the noisy environment and/or incubator possibly impairs proper interaction. Current monitor alarms produce sound at or above $480 \mathrm{~Hz}$, which is within the frequency range of newborn babies' cries [67]. These characteristics are certainly useful to attract the staff's attention, but they may impair newborn and parental comfort or rest.

\subsection{Strengths and Limitations of This Study}

This study characterizes the acoustic properties of the Giraffe Omnibed (GE Healthcare, Ohmeda Medical, Laurel, MD, USA) incubator. Since the retrieved data concerning the sound pressure level inside the incubator and the frequency response have been shown to be reproducible in a semi-anechoic room, different offices, and the NICU, the data that are presented seem to be robust and transferable to similar incubator models as well. The bit depth of 16 bit and a sampling rate of at least $48 \mathrm{kHz}$ is far higher than in most studies where there were no continuous measurements. This approach enables us to estimate the acoustic environment of a newborn inside the incubator. However, the microphones that were used for recordings limited the frequency spectra, which we could analyze to a bandwidth between $80 \mathrm{~Hz}$ and $1.5 \mathrm{kHz}$, not taking into account higher or lower frequencies that still might play a role. Additionally, the acoustic properties of the architecture at our NICU have not been analyzed, and the modification of sound generated by the newborn inside the incubator has not been studied. With the measurement of frequencies and sound pressure levels, we cannot distinguish between meaningful sound exposure and disturbing noise, and we did not perform any long-term measurements. This study offers several approaches to reduce noise such as taking into account potential noise sources (i.e., cabinet doors, incubator ports, visiting rounds); however, we have not developed any concrete solution to this problem. The evaluation of long-term effects of acoustic improvements on the baby would be the most interesting data, which is still open for further investigation.

\subsection{Conclusions for the Newborn inside the Incubator}

We assume that with a baby inside, especially if the baby is sick, repetitive opening and closing of the incubator ports will be the most important noise source. If a baby does not have to be accessed, opening and closing of the cabinet doors or drawers were the most important source of mechanical, loud, unpredictable $(>65 \mathrm{~dB})$, and short sudden $(<0.4 \mathrm{~s})$ noise. Although there may be interindividual, situational, and cultural differences with respect to the definition of a pleasant or unpleasant acoustic surrounding, there is still a consensus that humans generally prefer clear rather than distorted sounds [68]. Our findings are in line with similar studies that identified a noise generation between 80 and $90 \mathrm{~dB}(\mathrm{~A})$ due to the incubator opening or closing, which have been reviewed extensively $[69,70]$. Unfortunately, these findings do not comply with the recommendations to maintain the combination of background and operational sound within an hourly equivalent continuous sound pressure level (SPL, Leq) of $50 \mathrm{~dB}$, referring to a weighted 
slow response. Moreover, the SPL of $55 \mathrm{~dB}$ should not be exceeded more than $10 \%$ of the time (110). Opening the incubator at one port does not comply with the recommendation that transient sounds shall not exceed $70 \mathrm{~dB}$. Depending on the attention of the listener, the amount of vowels in the input sound, and the frequency spectrum which is used, speech has shown to be intelligible if the sound pressure level is about 9-18 dB [71] higher than the background sound pressure level and can be predicted according to the international standard IEC 60,268 [72]. Structured, repetitive prosodic patterns seem to be most important for language learning [73]. However, the acoustic environment of preterm infants is rather characterized by unstructured, sudden and unpredictable noise sources. Knowing that at $1 \mathrm{kHz}$ and above $40 \mathrm{~dB}$, the perceived loudness doubles if the sound pressure level is increased by $9 \mathrm{~dB}$ [33], it visualizes that the loudness perceived by preterm infants increases substantially by minor manipulations such as accessing the baby, by alarms, or cabinet use. This is because perceived loudness roughly doubles with each $10 \mathrm{~dB}$ increase in SPL (more accurately, it doubles with each $9 \mathrm{~dB}$ increase in SPL at $1 \mathrm{kHz}$ and above $40 \mathrm{~dB}$ ). Children need a higher signal-to-noise ratio to perceive speech correctly [74], making it likely that precisely articulated meaningful sound exposure such as with "motherese" or "infant-directed speech" [75] is necessary for the neurodevelopment of newborns as well. However, the evaluation of Caskey et al. [7] revealed that language exposure only contributed for up to $5 \pm 3 \%$ of sound recordings at an NICU, which increased with gestational age. This means that a premature baby in a closed incubator is largely isolated from conversations in the NICU but not from loud noises produced in the unit. In our unit, the parents normally come for $1-3 \mathrm{~h}$ a day to care for their child. On average, they might talk or sing to their baby for about $1 \mathrm{~h}$ daily. Assuming 12 caring procedures per day in the extremely premature, the staff will probably additionally talk for 5 min during each of these procedures. Altogether, this might lead to a meaningful exposure to sound during $8 \%$ of the daytime. The rest of the day, they will experience a mixture of sound and noise with both background noise, technical alarms, and medical discussions. Interestingly, EEG data deriving out of adult patients in the ICU suggest that REM sleep is most severely affected by the ICU surrounding [16]. Since the percentage of REM sleep is significantly higher in newborns compared to adults, this finding of sleep disturbance raises additional concern. When compared to other NICUs, our open bay NICU with an average SPL of $53 \mathrm{~dB}(\mathrm{~A})$ does not seem to be a loud one; the staff is trained to lower their voices, we offer music therapy, and we encourage parents to communicate with their newborns. Correspondingly, in a recent study in Montreal even after change of the whole NICU architecture, an average sound pressure level of $49 \mathrm{~dB}(\mathrm{~A})$ (coming from $58 \mathrm{~dB}(\mathrm{~A})$ ) has been reported [76]. Similar ranges have been reported in South India [77].

Depending on the child, some nurses observed that during the most common visiting hours such as during the weekends or if several urgency admissions took place, their newborns showed a higher rate of apnea and higher arousal frequencies.

Considering that newborn exposure to meaningful sounds contributes to their language acquisition and is essential for newborn development [78], our findings raise concerns and demand improvements in incubator technology and acoustic architecture at NICUs. Both human factors (staff and families), direct (incubator) and indirect infant and personnel surroundings (building properties, drawers, wardrobes), as well as technical equipment (ventilators, monitoring) have to be considered. The staff and families need continuous education to reduce their sound pressure levels during interactive speech but to increase the levels and open the incubator ports if the talk is directed to the newborns. While direct speech provides a very broad frequency range between $20 \mathrm{~Hz}$ and $20 \mathrm{kHz}$, microphones and loud speakers display a spectral narrowing (displayed by respective provider). Alarm levels should be reduced, and incubator ports and drawers have to be opened gently. Some background noise will always be audible, but it will be interpreted differently depending on the infant's health state and genetic background. Consequently, effort should be made both to monitor and to decrease noise sources, for example via portable applications $[79,80]$. In addition, meaningful acoustic stimulation of preterm 
babies in an NICU should be increased, providing vibroacoustic enrichment by meaningful auditory stimulation and social contact with infant-directed music and parental empowerment to speak and sing for their infants [6,81]. Offering zones where staff and/or parents can communicate and discuss with each other without disturbing the infants sleep is of great interest. Moreover, the definition of a "good acoustic environment" through only a weighted sound pressure level threshold should be revised, taking into account the quality of the sound. The ultimate goal will be to balance sounds and shape the preterm acoustic environment according to the infants' multi-sensory and social needs.

Author Contributions: Conceptualization, T.R., M.G., D.B., V.K. and F.B.H.; methodology, M.G., V.K., T.R.; software, M.G.; validation, M.G., V.K., T.R. and F.S.; formal analysis, M.G.; investigation, M.G.; resources, M.G., T.R., V.K., D.B.; data curation, M.G.; writing-original draft preparation, M.G., T.R., F.S.; writing-review and editing, F.S., F.B.H., T.R., M.G.; visualization, F.S., M.G.; supervision, T.R., F.B.H., D.B.; project administration, D.B., V.K., T.R.; funding acquisition, V.K., D.B. All authors have read and agreed to the published version of the manuscript.

Funding: This study was investigator initiated and carried out with institutional funding from the University Hospital of Zurich and the University of Zurich.

Institutional Review Board Statement: Not applicable.

Informed Consent Statement: Not applicable.

Acknowledgments: Anandic Medical Systems AG provided an empty incubator on loan for the acoustic measurements in the semi-anechoic room. We thank Oliver Weber who made this possible. We thank Felicia Gray for proofreading and language editing of the manuscript.

Conflicts of Interest: The authors declare no conflict of interest.

\section{Appendix A}

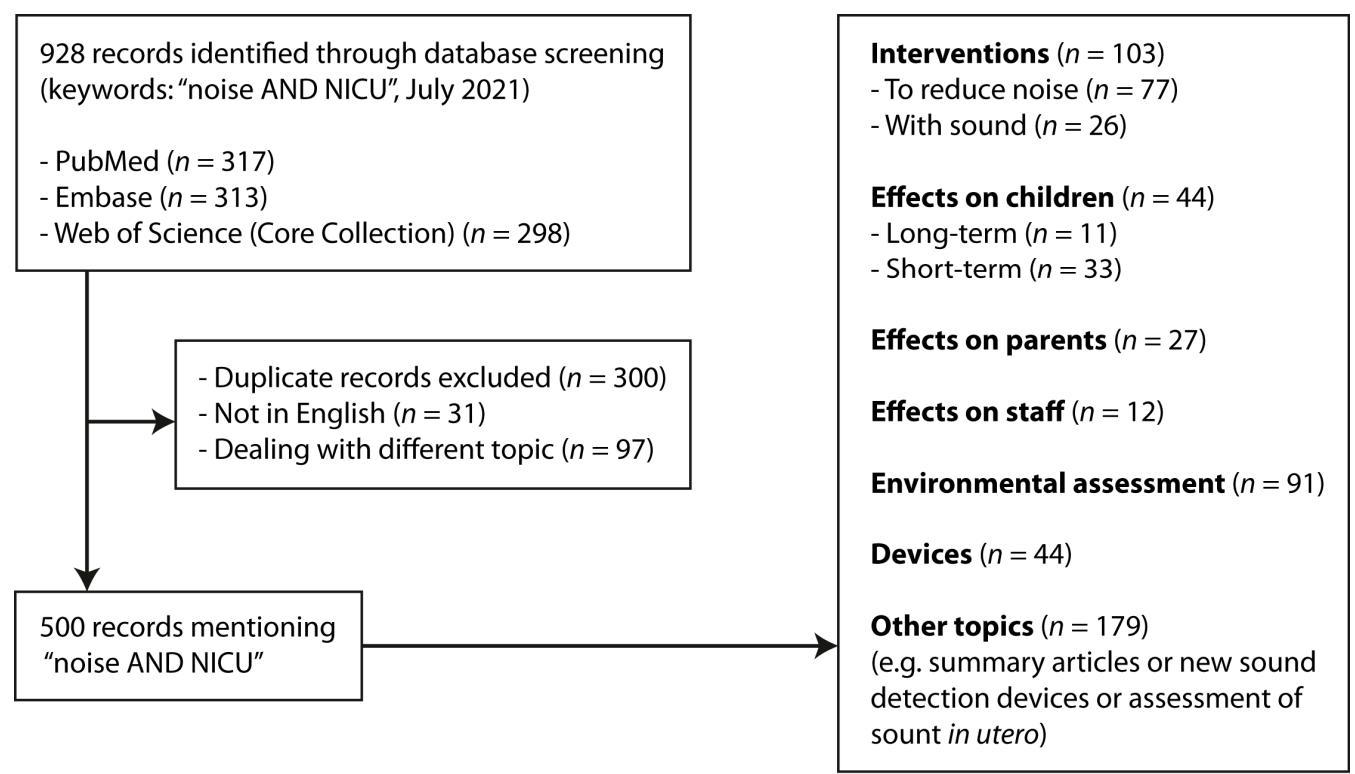

Figure A1. Literature review about "noise AND NICU" according to the PRISMA guideline.

\section{References}

1. Kuhn, P.; Zores, C.; Langlet, C.; Escande, B.; Astruc, D.; Dufour, A. Moderate acoustic changes can disrupt the sleep of very preterm infants in their incubators. Acta Paediatr. 2013, 102, 949-954. [CrossRef] [PubMed]

2. Wroblewska-Seniuk, K.; Greczka, G.; Dabrowski, P.; Szyfter-Harris, J.; Mazela, J. Hearing impairment in premature newbornsAnalysis based on the national hearing screening database in Poland. PLoS ONE 2017, 12, e0184359. [CrossRef] [PubMed]

3. Perlman, J.M. Neurobehavioral deficits in premature graduates of intensive care-potential medical and neonatal environmental risk factors. Pediatrics 2001, 108, 1339-1348. [CrossRef] [PubMed] 
4. Chang, E.F. Environmental Noise Retards Auditory Cortical Development. Science 2003, 300, 498-502. [CrossRef]

5. Pineda, R.G.; Neil, J.; Dierker, D.; Smyser, C.D.; Wallendorf, M.; Kidokoro, H.; Reynolds, L.C.; Walker, S.; Rogers, C.; Mathur, A.M.; et al. Alterations in brain structure and neurodevelopmental outcome in preterm infants hospitalized in different neonatal intensive care unit environments. J. Pediatr. 2014, 164, 52-60.e2. [CrossRef]

6. Haslbeck, F.B.; Jakab, A.; Held, U.; Bassler, D.; Bucher, H.U.; Hagmann, C. Creative music therapy to promote brain function and brain structure in preterm infants: A randomized controlled pilot study. Neuroimage Clin. 2020, 25, 102171. [CrossRef]

7. Caskey, M.; Stephens, B.; Tucker, R.; Vohr, B. Importance of parent talk on the development of preterm infant vocalizations. Pediatrics 2011, 128, 910-916. [CrossRef]

8. Abrams, R.M.; Gerhardt, K.J. The acoustic environment and physiological responses of the fetus. J. Perinatol. 2000, 20, S31-S36. [CrossRef]

9. Hepper, P.G.; Shahidullah, B.S. Development of fetal hearing. Arch. Dis. Child. Fetal. Neonatal. Ed. 1994, 71, F81-F87. [CrossRef]

10. ACOG Committee on Obstetric Practice. Guidelines for Perinatal Care, 7th ed.; American Academy of Pediatrics: Itasca, IL, USA, 2012.

11. Levy, G.D.; Woolston, D.J.; Browne, J.V. Mean noise amounts in level II vs level III neonatal intensive care units. Neonatal. Netw. 2003, 22, 33-38. [CrossRef] [PubMed]

12. Mankin, R.W. Acoustical detection of Aedes taeniorhynchus swarms and emergence exoduses in remote salt marshes. J. Am. Mosq. Control. Assoc. 1994, 10, 302-308.

13. Almadhoob, A.; Ohlsson, A. Sound reduction management in the neonatal intensive care unit for preterm or very low birth weight infants. Cochrane Database Syst. Rev. 2020, 1, CD010333. [CrossRef]

14. Thomas, K.A.; Martin, P.A. NICU sound environment and the potential problems for caregivers. J. Perinatol. 2000, 20, S94-S99. [CrossRef]

15. Verderber, S.; Gray, S.; Suresh-Kumar, S.; Kercz, D.; Parshuram, C. Intensive Care Unit Built Environments: A Comprehensive Literature Review (2005-2020). HERD 2021. [CrossRef] [PubMed]

16. Elbaz, M.; Leger, D.; Sauvet, F.; Champigneulle, B.; Rio, S.; Strauss, M.; Chennaoui, M.; Guilleminault, C.; Mira, J.P. Sound level intensity severely disrupts sleep in ventilated ICU patients throughout a 24-h period: A preliminary 24-h study of sleep stages and associated sound levels. Ann. Intensive Care 2017, 7, 25. [CrossRef] [PubMed]

17. Bry, A.; Wigert, H. Psychosocial support for parents of extremely preterm infants in neonatal intensive care: A qualitative interview study. BMC Psychol. 2019, 7, 76. [CrossRef] [PubMed]

18. Hutchinson, G.; Du, L.; Ahmad, K. Incubator-based Sound Attenuation: Active Noise Control In A Simulated Clinical Environment. PLoS ONE 2020, 15, e0235287. [CrossRef]

19. Pineda, R.; Guth, R.; Herring, A.; Reynolds, L.; Oberle, S.; Smith, J. Enhancing sensory experiences for very preterm infants in the NICU: An integrative review. J. Perinatol. 2017, 37, 323-332. [CrossRef]

20. Filippa, M.; Panza, C.; Ferrari, F.; Frassoldati, R.; Kuhn, P.; Balduzzi, S.; D’Amico, R. Systematic review of maternal voice interventions demonstrates increased stability in preterm infants. Acta Paediatr. 2017, 106, 1220-1229. [CrossRef] [PubMed]

21. Monson, B.B.; Rock, J.; Cull, M.; Soloveychik, V. Neonatal intensive care unit incubators reduce language and noise levels more than the womb. J. Perinatol. 2020, 40, 600-606. [CrossRef]

22. Blennow, G.; Svenningsen, N.W.; Almquist, B. Noise levels in infant incubators (adverse effects?). Pediatrics 1974, 53, $29-32$.

23. Fernandez Zacarias, F.; Beira Jimenez, J.L.; Bustillo Velazquez-Gaztelu, P.J.; Hernandez Molina, R.; Lubian Lopez, S. Noise level in neonatal incubators: A comparative study of three models. Int. J. Pediatr. Otorhinolaryngol. 2018, 107, 150-154. [CrossRef]

24. Parra, J.; de Suremain, A.; Berne Audeoud, F.; Ego, A.; Debillon, T. Sound levels in a neonatal intensive care unit significantly exceeded recommendations, especially inside incubators. Acta Paediatr. 2017, 106, 1909-1914. [CrossRef] [PubMed]

25. Berglund, B.; Lindvall, T.; Schwela, D.H. Guidelines for Community Noise; World Health Organization: Geneva, Switzerland, 1999.

26. Noise: A hazard for the fetus and newborn. American Academy of Pediatrics. Committee on Environmental Health. Pediatrics 1997, 100, 724-727.

27. Graven, S.N. Sound and the developing infant in the NICU: Conclusions and recommendations for care. J. Perinatol. 2000, 20, S88-S93. [CrossRef]

28. White, R.D. Recommended standards for the newborn ICU. J. Perinatol. 2007, 27, S4-S19. [CrossRef] [PubMed]

29. White, R.D.; Consensus Committee on Recommended Design Standards for Advanced Neonatal Care. Recommended standards for newborn ICU design, 9th edition. J. Perinatol. 2020, 40, 2-4. [CrossRef]

30. Crandall, I.B.; MacKenzie, D. Analysis of the Energy Distribution in Speech. Physical. Rev. 1922, 19, 221-232. [CrossRef]

31. Cox, R.V.; Neto, S.F.D.C.; Lamblin, C.; Sherif, M.H. ITU-T coders for wideband, superwideband, and fullband speech communication [Series Editorial]. IEEE Commun. Mag. 2009, 47, 106-109. [CrossRef]

32. Liu, C.; Fu, Q.J.; Narayanan, S.S. Effect of bandwidth extension to telephone speech recognition in cochlear implant users. J. Acoust. Soc. Am. 2009, 125, EL77-EL83. [CrossRef]

33. Fletcher, H. Physical measurements of audition and their bearing on the theory of hearing. Bell Syst. Tech. J. 1923, 2, 145-180. [CrossRef]

34. Allen, J.B. Harvey Fletcher's role in the creation of communication acoustics. J. Acoust. Soc. Am. 1996, 99, 1825-1839. [CrossRef]

35. French, N.R.; Steinberg, J.C. Factors Governing the Intelligibility of Speech Sounds. J. Acoust. Soc. Am. 1947, 19, 90-119. [CrossRef] 
36. Liao, J.; Liu, G.; Xie, N.; Wang, S.; Wu, T.; Lin, Y.; Hu, R.; He, H.G. Mothers' voices and white noise on premature infants' physiological reactions in a neonatal intensive care unit: A multi-arm randomized controlled trial. Int. J. Nurs. Stud. 2021, 119, 103934. [CrossRef]

37. Gadeke, R.; Doring, B.; Keller, F.; Vogel, A. The noise level in a childrens hospital and the wake-up threshold in infants. Acta Paediatr. Scand. 1969, 58, 164-170. [CrossRef] [PubMed]

38. Zimmerman, E.; Lahav, A. Ototoxicity in preterm infants: Effects of genetics, aminoglycosides, and loud environmental noise. J. Perinatol. 2013, 33, 3-8. [CrossRef]

39. Bellieni, C.V.; Buonocore, G.; Pinto, I.; Stacchini, N.; Cordelli, D.M.; Bagnoli, F. Use of sound-absorbing panel to reduce noisy incubator reverberating effects. Biol. Neonate 2003, 84, 293-296. [CrossRef] [PubMed]

40. Abou Turk, C.; Williams, A.L.; Lasky, R.E. A randomized clinical trial evaluating silicone earplugs for very low birth weight newborns in intensive care. J. Perinatol. 2009, 29, 358-363. [CrossRef] [PubMed]

41. Freudenthal, A.; van Stuijvenberg, M.; van Goudoever, J.B. A quiet NICU for improved infants' health, development and well-being: A systems approach to reducing noise and auditory alarms. Cogn. Technol. Work 2012, 15, 329-345. [CrossRef]

42. Casey, L.; Fucile, S.; Flavin, M.; Dow, K. A two-pronged approach to reduce noise levels in the neonatal intensive care unit. Early Hum. Dev. 2020, 146, 105073. [CrossRef]

43. Busch-Vishniac, I.J.; West, J.E.; Barnhill, C.; Hunter, T.; Orellana, D.; Chivukula, R. Noise levels in Johns Hopkins Hospital. J. Acoust. Soc. Am. 2005, 118, 3629-3645. [CrossRef]

44. Darcy, A.E.; Hancock, L.E.; Ware, E.J. A descriptive study of noise in the neonatal intensive care unit: Ambient levels and perceptions of contributing factors. Adv. Neonatal Care Off. J. Natl. Assoc. Neonatal. Nurses 2008, 8, S16-S26. [CrossRef]

45. Lasky, R.E.; Williams, A.L. Noise and light exposures for extremely low birth weight newborns during their stay in the neonatal intensive care unit. Pediatrics 2009, 123, 540-546. [CrossRef]

46. Berg, A.L. Monitoring Noise Levels in a Tertiary Neonatal. Intensive Care Unit. Contemp. Issues Commun. Sci. Disord. 2010, 37, 69-72. [CrossRef]

47. O'Callaghan, N.; Dee, A.; Philip, R.K. Evidence-based design for neonatal units: A systematic review. Matern Health Neonatol. Perinatol. 2019, 5, 6. [CrossRef] [PubMed]

48. van Veenendaal, N.R.; van Kempen, A.; Franck, L.S.; O’Brien, K.; Limpens, J.; van der Lee, J.H.; van Goudoever, J.B.; van der Schoor, S.R.D. Hospitalising preterm infants in single family rooms versus open bay units: A systematic review and meta-analysis of impact on parents. EClinicalMedicine 2020, 23, 100388. [CrossRef] [PubMed]

49. Liu, W.F. Comparing sound measurements in the single-family room with open-unit design neonatal intensive care unit: The impact of equipment noise. J. Perinatol. 2012, 32, 368-373. [CrossRef] [PubMed]

50. Van Enk, R.A.; Steinberg, F. Comparison of private room with multiple-bed ward neonatal intensive care unit. HERD 2011, 5, 52-63. [CrossRef] [PubMed]

51. Chen, H.L.; Chen, C.H.; Wu, C.C.; Huang, H.J.; Wang, T.M.; Hsu, C.C. The influence of neonatal intensive care unit design on sound level. Pediatr. Neonatol 2009, 50, 270-274. [CrossRef]

52. Stevens, D.C.; Akram Khan, M.; Munson, D.P.; Reid, E.J.; Helseth, C.C.; Buggy, J. The impact of architectural design upon the environmental sound and light exposure of neonates who require intensive care: An evaluation of the Boekelheide Neonatal. Intensive Care Nursery. J. Perinatol. 2007, 27, S20-S28. [CrossRef]

53. Stevens, D.C.; Helseth, C.C.; Thompson, P.A.; Pottala, J.V.; Khan, M.A.; Munson, D.P. A Comprehensive Comparison of Open-Bay and Single-Family-Room Neonatal. Intensive Care Units at Sanford Children's Hospital. HERD 2012, 5, 23-39. [CrossRef]

54. Stevens, D.; Thompson, P.; Helseth, C.; Pottala, J. Mounting evidence favoring single-family room neonatal intensive care. J. Neonatal. Perinat. Med. 2015, 8, 177-178. [CrossRef]

55. Surenthiran, S.S.; Wilbraham, K.; May, J.; Chant, T.; Emmerson, A.J.; Newton, V.E. Noise levels within the ear and post-nasal space in neonates in intensive care. Arch. Dis. Child. Fetal. Neonatal. Ed. 2003, 88, F315-F318. [CrossRef] [PubMed]

56. Hoehn, T.; Busch, A.; Krause, M.F. Comparison of noise levels caused by four different neonatal high-frequency ventilators. Intensive Care Med. 2000, 26, 84-87. [CrossRef] [PubMed]

57. Kazemizadeh Gol, M.A.; Black, A.; Sidman, J. Bone conduction noise exposure via ventilators in the neonatal intensive care unit. Laryngoscope 2015, 125, 2388-2392. [CrossRef] [PubMed]

58. Herrmann, B.; Augereau, T.; Johnsrude, I.S. Neural Responses and Perceptual Sensitivity to Sound Depend on Sound-Level Statistics. Sci. Rep. 2020, 10, 9571. [CrossRef]

59. Job, R.F.; Hatfield, J.; Carter, N.L.; Peploe, P.; Taylor, R.; Morrell, S. General scales of community reaction to noise (dissatisfaction and perceived affectedness) are more reliable than scales of annoyance. J. Acoust. Soc. Am. 2001, 110, 939-946. [CrossRef]

60. Pavlov, I.P. Conditioned Reflexes: An Investigation of the Physiological Activity of the Cerebral Cortex; Oxford Univ. Press: Oxford, UK, 1927; pp. xv, 430-xv, 430.

61. Lim, N. Cultural differences in emotion: Differences in emotional arousal level between the East and the West. Integr. Med. Res. 2016, 5, 105-109. [CrossRef]

62. Kliuchko, M.; Heinonen-Guzejev, M.; Vuust, P.; Tervaniemi, M.; Brattico, E. A window into the brain mechanisms associated with noise sensitivity. Sci. Rep. 2016, 6, 39236. [CrossRef] [PubMed]

63. Heinonen-Guzejev, M.; Vuorinen, H.S.; Mussalo-Rauhamaa, H.; Heikkila, K.; Koskenvuo, M.; Kaprio, J. Genetic component of noise sensitivity. Twin Res. Hum. Genet. 2005, 8, 245-249. [CrossRef] 
64. Brezmes-Raposo, M.; Bermudez, L.; Dominguez, C.; Fernandez, C.; Franco, A.; Villa, C.; Sanz, I.; Pino-Vazquez, A. P0503/\#2118: Caring for the invisible. how to humanize clinical care in a pediatric and neonatal intensive care unit. Pediatric. Crit. Care Med. 2021, 22, 253.

65. Wielek, T.; Del Giudice, R.; Lang, A.; Wislowska, M.; Ott, P.; Schabus, M. On the development of sleep states in the first weeks of life. PLoS ONE 2019, 14, e0224521. [CrossRef] [PubMed]

66. Saliba, S.; Esseily, R.; Filippa, M.; Gratier, M.; Grandjean, D. Changes in the vocal qualities of mothers and fathers are related to preterm infant's behavioural states. Acta Paediatr. 2020, 109, 2271-2277. [CrossRef] [PubMed]

67. Shinya, Y.; Kawai, M.; Niwa, F.; Imafuku, M.; Myowa, M. Fundamental Frequency Variation of Neonatal. Spontaneous Crying Predicts Language Acquisition in Preterm and Term Infants. Front. Psychol. 2017, 8, 2195. [CrossRef]

68. McDermott, J.H.; Schultz, A.F.; Undurraga, E.A.; Godoy, R.A. Indifference to dissonance in native Amazonians reveals cultural variation in music perception. Nature 2016, 535, 547-550. [CrossRef]

69. Olejnik, B.K. Inadvertent Noise in Neonatal. Intensive Care Unit and its Impact on Prematurely Born Infants. Biomed. J. Sci. Tech Res. 2018, 11. [CrossRef]

70. Bertsch, M.; Reuter, C.; Czedik-Eysenberg, I.; Berger, A.; Olischar, M.; Bartha-Doering, L.; Giordano, V. The "Sound of Silence" in a Neonatal. Intensive Care Unit-Listening to Speech and Music Inside an Incubator. Front. Psychol. 2020, 11, 1055. [CrossRef]

71. Meyer, J.; Dentel, L.; Meunier, F. Speech recognition in natural background noise. PLoS ONE 2013, 8, e79279. [CrossRef]

72. International Electrotechnical Commission. IEC 60268-16:2020 Sound System Equipment-Part 16: Objective Rating of Speech Intelligibility by Speech Transmission Index, 5th ed.; International Electrotechnical Commission: Geneva, Switzerland, 2020.

73. Kuhl, P.K. Early language acquisition: Cracking the speech code. Nat. Rev. Neurosci. 2004, 5, 831-843. [CrossRef]

74. Trehub, S.E.; Bull, D.; Schneider, B.A. Infants' detection of speech in noise. J. Speech Hear. Res. 1981, 24, 202-206. [CrossRef]

75. Spinelli, M.; Fasolo, M.; Mesman, J. Does prosody make the difference? A meta-analysis on relations between prosodic aspects of infant-directed speech and infant outcomes. Dev. Rev. 2017, 44, 1-18. [CrossRef]

76. Aita, M.; Robins, S.; Charbonneau, L.; Doray-Demers, P.; Feeley, N. Comparing light and noise levels before and after a NICU change of design. J. Perinatol. 2021. [CrossRef]

77. Ramesh, A.; Denzil, S.B.; Linda, R.; Josephine, P.K.; Nagapoornima, M.; Suman Rao, P.N.; Swarna Rekha, A. Maintaining reduced noise levels in a resource-constrained neonatal intensive care unit by operant conditioning. Indian Pediatr. 2013, 50, 279-282. [CrossRef] [PubMed]

78. Ruben, R.J. The Ontogeny of Human Hearing. Acta Oto-Laryngol. 1992, 112, 192-196. [CrossRef] [PubMed]

79. Gilmour, D.; Duong, K.M.; Gilmour, I.J.; Davies, M.W. NeoSTRESS: Study of Transfer and Retrieval Environmental Stressors upon neonates via a smartphone application-Sound. J. Paediatr. Child. Health 2020, 56, 1396-1401. [CrossRef] [PubMed]

80. Capriolo, C.; Viscardi, R.M.; Broderick, K.A.; Nassebeh, S.; Kochan, M.; Solanki, N.S.; Leung, J.C. Assessment of Neonatal. Intensive Care Unit Sound Exposure Using a Smartphone Application. Am. J. Perinatol. 2020. [CrossRef]

81. Haslbeck, F.B.; Bassler, D. Music From the Very Beginning-A Neuroscience-Based Framework for Music as Therapy for Preterm Infants and Their Parents. Front. Behav. Neurosci. 2018, 12, 112. [CrossRef] 